\title{
Inibição da ação do etileno retarda o desenvolvimento de injúrias de frio em tangor 'Murcott'
}

\author{
Inhibition of ethylene action delay chilling injury development in tangor 'Murcott'
}

\author{
Fernando Kazuhiro Edagi ${ }^{\mathrm{I}}$ Maria Luiza Lye Jomori ${ }^{\mathrm{I}}$ Ricardo Alfredo Kluge \\ Giuseppina Pace Pereira Lima ${ }^{\mathrm{II}}$ Ricardo Antunes Azevedo ${ }^{\mathrm{III}}$ Ivan Sestari $^{{ }^{*}}$
}

\section{RESUMO}

O bloqueio de eventos dependentes da sinalização do etileno pode afetar de maneira positiva ou negativa a qualidade de frutos tropicais após o armazenamento refrigerado. Dessa forma, os objetivos do presente trabalho foram estudar o envolvimento do etileno no desenvolvimento de injúrias de frio em tangor 'Murcott' e avaliar as respostas envolvidas no processo de resistência às injúrias. Os frutos foram expostos a 500nL $L^{-1}$ de 1-metilciclopropeno (1-MCP) durante 12 horas ou imersos em soluções contendo 2000nL $L^{-1}$ de ethephon ou ácido salicílico durante cinco minutos antes de serem armazenados a $1^{\circ} \mathrm{C}$, por 90 dias. Como controle, parte dos frutos foi armazenada a $1^{\circ} \mathrm{C}$. O tratamento de frutos com ethephon ou ácido salicílico antecipou e intensificou as injúrias de frio. Por outro lado, a inibição do etileno pelo 1-MCP retardou o surgimento dos sintomas $e$ resultou em menor índice de injúrias e percentual de frutos podres ao final do armazenamento. A atividade da superóxido dismutase (SOD) foi intensificada aos 45 dias, contudo em menor intensidade nos frutos tratados com ácido salicílico. Nas avaliações subsequentes, houve decréscimo na atividade da SOD em todos os tratamentos, porém aos 90 dias a intensidade manteve-se levemente superior à observada nos primeiros 30 dias de armazenamento. Os teores de putrescina (Put) e espermina (Spm), no flavedo dos frutos, não sofreram significativa alteração durante o armazenamento. Em contrapartida, os teores de espermidina ( $S p d)$ foram mais afetados pelo estresse ocasionado pelo frio.

Palavras-chave: 1-metilciclopropeno, estresse oxidativo, poliaminas.

\section{ABSTRACT}

The blockage of ethylene-dependent signaling may affect the quality of tropical fruit in a positive or negative way after cold storage. Hence, the role of ethylene on chilling injury in tangor 'Murcott' and the responses related to injuries resistance were the aims of this study. Fruit were treated for $12 \mathrm{~h}$ with $500 \mathrm{~nL}$ $L^{-1}$ of 1-methylcyclopropene (1-MCP) or immersed into solutions containing 2000nL $\mathrm{L}^{-1}$ ethephon or salicylic acid for $5 \mathrm{~min}$ before storage at $1^{\circ} \mathrm{C}$ for 90 days. As a control fruit were stored at $1^{\circ} \mathrm{C}$. Chilling injury symptoms were anticipated and intensified when fruit were treated with ethephon or salicylic acid. On the other hand, the ethylene inhibition by 1-MCP delayed symptoms and resulted in the lowest injury index and percentage of fruit decay at the end of storage. At 45 days the superoxide dismutase (SOD) activity was intensified, however, in lower intensity in salicylic acid treated fruit. Afterwards, SOD activity decrease in all the treatments, though at 90 days the intensity was slightly superior to that at the initial 30 days of storage. During storage period it were not observed significantly alterations in putrescine (Put) and spermine (Spm) levels in flavedo tissues. In contrast, spermidine (Spm) levels were more affected by chilling stress.

Key words: 1-methylcyclopropene, oxidative stress, polyamines.

\section{INTRODUÇÃO}

A sensibilidade de frutos de origem tropical e subtropical a temperaturas inferiores a $10^{\circ} \mathrm{C}$ impõe

IDepartamento de Ciências Biológicas, Escola Superior de Agricultura "Luiz de Queiroz" (ESALQ), Universidade de São Paulo (USP), CP 9, 13418-900, Piracicaba, SP, Brasil. E-mail: isestari@esalq.usp.br. *Autor para correspondência.

IIInstituto de Biociências, Universidade Estadual Paulista (UNESP), Botucatu, SP, Brasil.

IIIDepartamento de Genética, ESALQ, USP, Piracicaba, SP, Brasil. 
limitações ao transporte de longa distância e à extensão da vida de prateleira. O tangor 'Murcott', assim como outros frutos cítricos, é sensível ao frio, podendo desenvolver sintomas de 'chilling' quando expostos a temperaturas entre 0 e $8^{\circ} \mathrm{C}$. À medida que o período de exposição dos tecidos ao frio é prolongado, os sintomas são exteriorizados, resultando dessa forma em implicações diretas na comercialização e aceitação desses frutos pelos consumidores.

Em consequência da exposição à baixa temperatura, são evidenciadas alterações no metabolismo normal dos frutos, as quais precedem os sintomas visuais e são traduzidas em acréscimos na atividade respiratória, na síntese de etileno e no decréscimo na funcionalidade das membranas celulares (WANG, 1982). Por essas razões, acredita-se que o dano às membranas seja o evento inicial no desenvolvimento das injúrias de frio (MARANGONI et al., 1996) e que os sintomas decorrem da geração de espécies reativas de oxigênio (EROS) em níveis acima da capacidade de remoção pelos tecidos (SALA, 1998). Recentemente, tem sido relatado que as poliaminas podem auxiliar a remoção de espécies reativas de oxigênio e atuar diretamente na estabilização das membranas celulares (LARHER et al., 2003; GROPPA \& BENAVIDES, 2008).

De modo geral, as plantas possuem um eficiente sistema composto por antioxidantes e enzimas capazes de prevenir o acúmulo de intermediários tóxicos do metabolismo celular (MITTLER, 2002). A enzima superóxido dismutase (SOD) desempenha papel central no processo de defesa contra o estresse oxidativo (MITTLER, 2002). Em tangerinas, SALA (1998) verificou que cultivares tolerantes ao dano de frio possuem um sistema antioxidante mais eficiente que as cultivares sensíveis. Dessa forma, tem sido sugerido que a maior capacidade de remoção de EROS pode estar envolvida na maior tolerância de tecidos vegetais a variados estresses (WISMER, 2003). Além disso, tem sido postulado que o etileno pode desempenhar importante papel na iniciação das injúrias de frio em frutos (LAFUENTE et al., 2001; SALVADOR et al., 2006. Contudo, a relação existente entre o etileno, as poliaminas e o dano de frio ainda é pouco compreendida. Em tangerinas 'Nova' e 'Ortanique' (SALVADOR et al., 2006) e em abacaxis (SELVARAJAH et al., 2001), o bloqueio da ação do etileno por meio do 1-MCP reduziu consideravelmente a incidência de injúrias de frio. Em contraste, os sintomas foram intensificados após a aplicação desse composto em laranjas (PORAT et al., 1999) e tangerinas 'Fortune' (LAFUENTE et al., 2001).
Dentro desse contexto, o trabalho teve como objetivos estudar o envolvimento do etileno no desenvolvimento de injúrias de frio em tangor 'Murcott' e avaliar as respostas envolvidas no processo de resistência às injúrias.

\section{MATERIAL E MÉTODOS}

Frutos de tangor 'Murcott' foram colhidos em pomar comercial localizado no município de Engenheiro Coelho, São Paulo (SP). Imediatamente após a colheita, os frutos foram transportados ao laboratório de Fisiologia e Bioquímica Pós-colheita da Escola Superior de Agricultura "Luiz de Queiroz", onde foram selecionados quanto ao tamanho, à uniformidade de coloração e à ausência de manchas na casca. Em seguida, as amostras foram divididas aleatoriamente, em quatro lotes de 240 frutos cada, e os seguintes tratamentos foram aplicados: armazenamento refrigerado a $1^{\circ} \mathrm{C}$ (controle); imersão dos frutos em solução contendo $2000 \mathrm{~nL} \mathrm{~L}^{-1}$ de ethephon $\left(\right.$ Ethrel $^{\circledR}$ ) durante cinco minutos; exposição dos frutos a 500nL $\mathrm{L}^{-1}$ de 1-metilciclopropeno (1-MCP) na temperatura de $25^{\circ} \mathrm{C}$, por 12 horas; e imersão dos frutos em solução contendo $2000 \mathrm{~nL} \mathrm{~L}^{-1}$ de ácido salicílico durante cinco minutos. Após a aplicação dos tratamentos, os frutos foram armazenados por 90 dias a $1^{\circ} \mathrm{C}\left( \pm 0,5^{\circ} \mathrm{C}\right)$, com $90 \%( \pm 5 \%)$ de UR. Durante o armazenamento, lotes de frutos foram removidos da refrigeração (aos 15, 30, 45, 60,75 e 90 dias) e expostos a $25^{\circ} \mathrm{C}$, por cinco dias, simulando o período de comercialização.

A incidência de injúrias de frio foi determinada de acordo a superfície da casca afetada (SALA \& LAFUENTE, 1999), em que: $0=$ sem dano, $1=$ pouco (1 a $5 \%$ ), 2=médio (5-25\%), 3=severo (25-50\%) e $4=$ muito severo $(>50 \%)$. A incidência de podridões foi determinada pela contagem de frutos que apresentavam lesões causadas por fungos patogênicos e expressa em percentual. A respiração e a síntese de etileno foram determinadas com auxílio de um cromatógrafo a gás, da marca Thermofinigan, modelo Trace GC, equipado com detector de ionização por chama (FID). As temperaturas da coluna, do injetor e do detector foram de 100,140 e $200^{\circ} \mathrm{C}$, respectivamente. A partir da concentração de etileno e $\mathrm{CO}_{2}$ acumulada no recipiente, do volume de ar livre do recipiente, da massa dos frutos e do tempo de fechamento do recipiente, foi calculada a síntese de etileno e a respiração dos frutos.

Em cada período de avaliação, amostras de flavedo de cada tratamento foram coletadas, congeladas em nitrogênio líquido e armazenadas a $80^{\circ} \mathrm{C}$, até o momento das análises. Aproximadamente 
um grama de flavedo congelado foi macerado em cadinho de porcelana com nitrogênio líquido. Em seguida, o tecido vegetal foi homogeneizado em tampão fosfato de potássio $100 \mathrm{mM}, \mathrm{pH} 7,5$, contendo $1 \mathrm{mM}$ de EDTA, $3 \mathrm{mM}$ de DTT e $4 \%$ (p/v) de PVPP. O homogeneizado foi centrifugado a $10000 \mathrm{~g}$ por 30 minutos, a $4^{\circ} \mathrm{C}$, e o sobrenadante foi coletado e estocado em freezer, a $-80^{\circ} \mathrm{C}$, até o momento das análises. A atividade da glutationa redutase (GR) foi determinada espectrofotometricamente a $30^{\circ} \mathrm{C}$, em uma mistura de reação, consistindo de tampão fosfato de potássio $100 \mathrm{mM}$, pH 7,5, contendo $1 \mathrm{mM}$ DTNB, $1 \mathrm{mM}$ GSSG e 0,1mM NADPH. A reação foi iniciada pela adição de $50 \mu \mathrm{L}$ de extrato. A GR foi estimada pela redução da glutationa oxidada, que foi monitorada pela alteração da absorbância a 412nm (SMITH et al., 1988). A atividade da superóxido dismutase foi determinada por eletroforese, conduzida a $4^{\circ} \mathrm{C}$ conforme descrito em VITÓRIA et al. (2001). Após a separação das proteínas, os géis foram enxaguados rapidamente em água destilada-deionizada e incubados no escuro, em temperatura ambiente, em uma mistura de reação contendo $50 \mathrm{mM}$ de tampão fosfato de potássio $\mathrm{pH}$ 7,8, 1mM EDTA, 0,05mM riboflavina, 0,1 mM NBT e $0,3 \%$ TEMED. Após 30 minutos, a mistura de reação foi removida e os géis foram enxaguados com água destilada-deionizada e colocados sob iluminação por alguns minutos. SOD bovina (Sigma) foi utilizada como padrão. As poliaminas foram determinadas seguindo a técnica modificada de LIMA et al. (1999). Amostras de flavedo foram homogeneizadas em ácido perclórico $5 \%$ gelado, por uma hora, em banho de gelo, e centrifugadas a $12000 \mathrm{~g}$, por 20 minutos. O sobrenadante contendo poliaminas livres foi usado para dansilação. Ao sobrenadante $(200 \mu \mathrm{L})$, foram adicionados $400 \mu \mathrm{L}$ de cloreto de dansila e $200 \mu \mathrm{L}$ de $\mathrm{Na}_{2} \mathrm{CO}_{3}$ saturado. Após agitação, a mistura permaneceu em temperatura ambiente, no escuro, por 16 horas. Foram usados $500 \mu \mathrm{L}$ para extrair as poliaminas dansiladas, e as alíquotas foram aplicadas em placas de cromatografia de camada delgada recobertas por sílica gel 60G-Merck. Os solventes cromatográficos empregados na fase móvel foram o clorofórmio e a trietilamina $(25: 2 \mathrm{v} / \mathrm{v})$. Padrões de poliaminas foram dansilados e cromatografados como descrito anteriormente e quantificados por meio de densitômetro (Helena). Os teores de poliaminas livres (putrescina, espermidina e espermina) foram expressos em nmol g-1 massa fresca-1. O conteúdo de proteínas totais foi determinado pelo método de BRADFORD (1976), utilizando-se BSA como padrão.

O delineamento foi o inteiramente casualizado, com quatro repetições de 10 frutos. Os dados com distribuição binomial foram transformados pela fórmula arco seno $(\mathrm{x} / 100)^{1 / 2}$, para serem normalizados. Os dados obtidos com distribuição normal foram testados quanto às pressuposições da análise da variância e então submetidos à ANOVA e, havendo diferenças, as médias foram comparadas pelo teste de Tukey $(\mathrm{P} \leq 0,05)$.

\section{RESULTADOS E DISCUSSÃO}

A aplicação de ethephon ou ácido salicílico nos frutos antecipou o surgimento das injúrias de frio em relação ao controle e aos frutos tratados com 1MCP (Figura 1A). Os danos devido à ação do frio iniciaram sua exteriorização no flavedo dos frutos tratados com ácido salicílico aos 15 dias de armazenamento a $1^{\circ} \mathrm{C}$. Em contraste, nos frutos tratados com 1-MCP, os sintomas foram visualizados somente após um mês de armazenamento e permaneceram significativamente inferiores aos demais tratamentos em todas as avaliações. Em conformidade com outros estudos realizados anteriormente, os resultados obtidos reforçam a hipótese de que o etileno desempenha importante papel na intensificação dos sintomas das injúrias de frio (PORAT et al., 1999; SELVARAJAH et al., 2001; SALVADOR et al., 2006). Todavia, o conjunto de eventos fisiológicos envolvidos nessa resposta ainda permanece pouco compreendido.

A incidência de podridões foi inferior a $5 \%$ ao final do armazenamento (Figura 1B). Nos frutos tratados com 1-MCP, a incidência manteve-se sempre inferior a dos demais tratamentos. Frutos tratados com ethephon ou ácido salicílico exibiram percentual de podridão semelhante ao controle até os 60 dias de armazenamento. Aos 75 e 90 dias, contudo, houve ligeiro acréscimo no percentual de podridões, nos frutos tratados com ácido salicílico. Recentemente estudos têm relatado a efetividade de compostos salicilados na redução das injúrias de frio (WANG et al., 2006; SAYYAR et al., 2009) e no desenvolvimento de podridões em frutos, por meio da regulação de aspectos ligados a estímulos ao sistema antioxidante de defesa e à produção de proteínas relacionadas à patogênese (XU \& TIAN 2008). Dessa forma, acreditase que a intensificação das injúrias de frio e a maior sensibilidade as podridões relatadas neste trabalho sejam decorrentes de efeito fitotóxico da dosagem utilizada para o tratamento dos frutos.

Houve significativo acréscimo na síntese de etileno a partir dos 15 dias a $1{ }^{\circ} \mathrm{C}$ nos frutos tratados com etileno (Figura 1C). A taxa manteve-se constante até os 75 dias, apresentando ligeiro declínio aos 90 

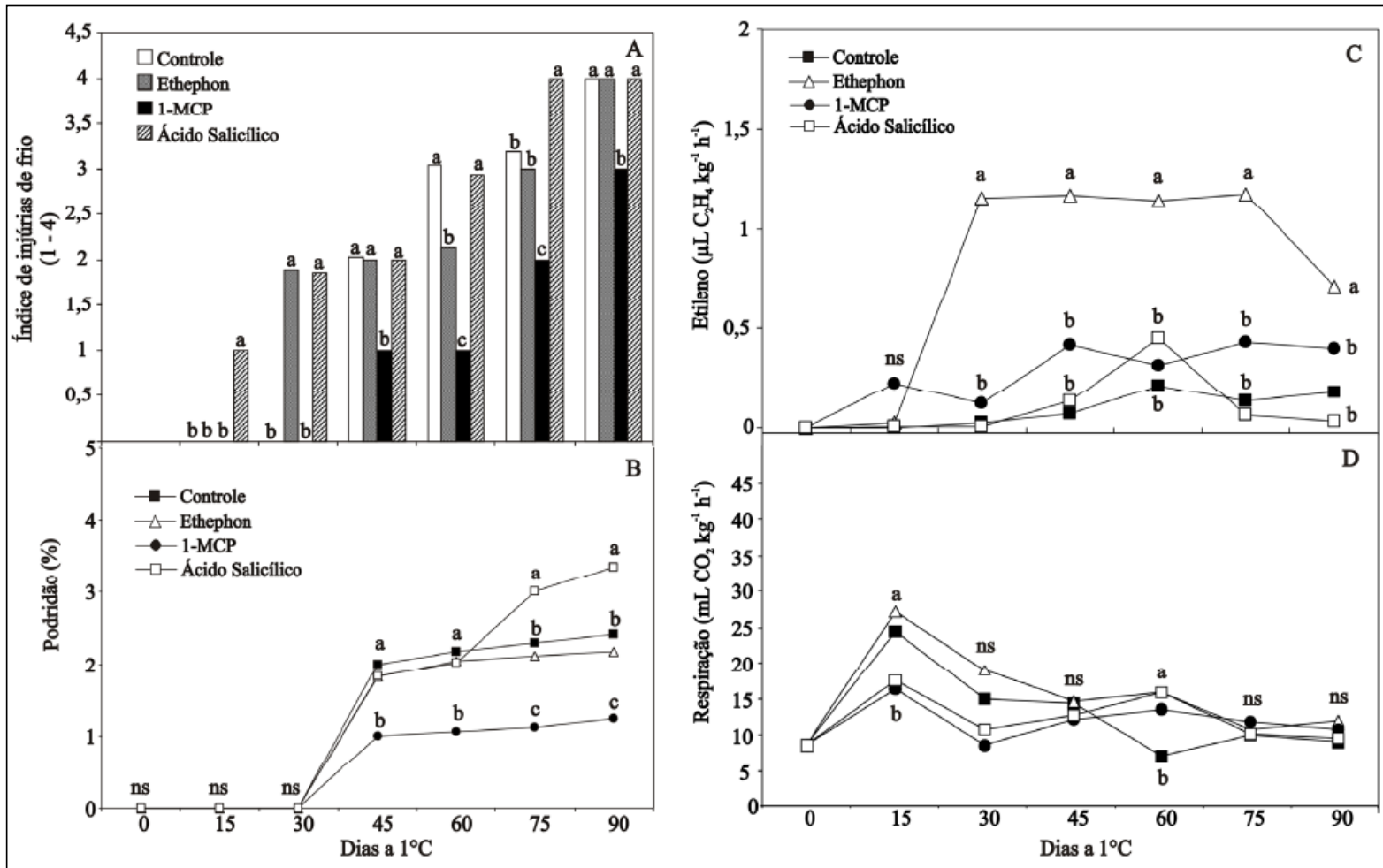

Figura 1 - Índice de injúrias de frio (A), percentual de podridão (B), síntese de etileno (C) e atividade respiratória (D) de tangor 'Murcott' tratado com ethephon, 1-MCP ou ácido salicílico e armazenado a $1{ }^{\circ} \mathrm{C}$, durante 90 dias. Tratamentos com médias não seguidas pela mesma letra diferem pelo teste de Tukey $(\mathrm{P} \leq 0,05)$; ns: diferença não significativa.

dias. Por outro lado, nos frutos submetidos aos demais tratamentos, a síntese de etileno permaneceu inferior a $0,5 \mu \mathrm{L} \mathrm{kg}^{-1} \mathrm{~h}^{-1}$ durante o armazenamento.

A atividade respiratória dos frutos não foi influenciada pelos tratamentos ao longo do armazenamento refrigerado (Figura 1D). Independente dos tratamentos aplicados verificou-se acréscimo na atividade respiratória dos frutos aos 15 dias a $1^{\circ} \mathrm{C} \mathrm{em}$ relação à colheita. Posteriormente, a atividade respiratória gradualmente diminuiu, atingindo taxa semelhante à observada na colheita.

A atividade da superóxido dismutase (SOD), determinada por meio da separação de isoenzimas por meio de eletroforese não desnaturante, revelou a existência de três isoenzimas no flavedo dos frutos (bandas I, II e III). As isoenzimas II e III foram observadas em todas as avaliações (Figura 2). Por outro lado, a atividade da isoenzima I foi observada apenas aos 45, 75 e 90 dias. Os frutos tratados com etileno e 1-MCP apresentaram superior acréscimo na intensidade das bandas das três isoenzimas aos 45 dias. Nas avaliações subsequentes, houve decréscimo na intensidade das bandas em todos os tratamentos, porém a intensidade manteve-se superior à intensidade observada aos 15 e 30 dias. Acréscimos na atividade da SOD têm sido associados à maior tolerância de frutos ao estresse desencadeado pelo frio devido a sua capacidade de combater a superprodução de radicais superóxido gerados em resposta ao estresse. No presente estudo, é importante salientar que a intensificação da atividade da SOD nos frutos tratados com 1-MCP foi concomitante com a exteriorização dos sintomas (Figura 1A e Figura 2). Por outro lado, nos frutos tratados com ethephon, a intensificação da atividade da SOD não foi suficientemente alta para remover os radicais superóxido, induzidos pelo etileno, o que pode ser confirmado pela antecipação do surgimento das injúrias de frio.

Os frutos tratados com 1-MCP apresentaram maior atividade da GR aos 15 dias, em comparação com os demais tratamentos (Figura 3). De maneira geral, houve acréscimo na atividade da GR em todos os tratamentos até os 45 dias. A partir desse período, verificou-se uma redução mais pronunciada na atividade da GR presente no flavedo dos frutos tratados com etileno ou 1-MCP. Contudo, os níveis permaneceram semelhantes aos demais tratamentos aos 60, 75 e 90 dias. Possivelmente, a maior atividade da GR verificada nos frutos tratados com 1-MCP, na primeira metade do período de armazenamento, tenha 


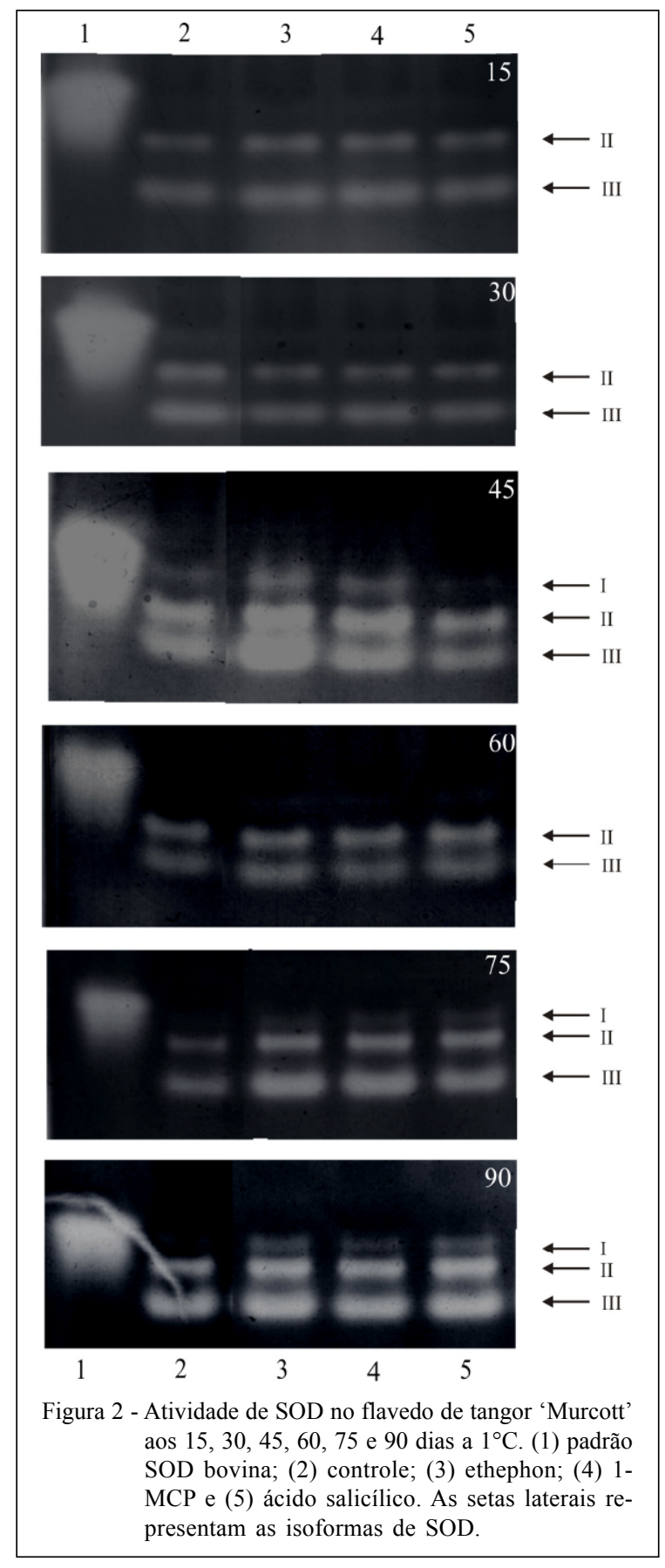

sido suficiente para manter a relação entre os níveis de glutationa oxidada e reduzida em níveis altos, contribuindo para a regeneração do ascorbato, o qual é necessário para a atividade da peroxidase dependente de ascorbato (GAMBLE \& BURKE, 1984; SALA, 1998).

O teor das poliaminas Put e Spm presentes no flavedo dos frutos não sofreu significativa alteração ao longo do armazenamento (Figuras 4A e 4B). O teor de Put permaneceu semelhante entre os tratamentos até os 45 dias a $1^{\circ} \mathrm{C}$. Aos 60 dias, o teor de Put foi superior nos frutos tratados com etileno, porém não diferiu do controle. Em limão, berinjela e pepino, estudos têm relatado que os níveis de Put aumentam com o surgimento das injúrias de frio (SERRANO et al., 1996; RODRIGUEZ et al., 2001; MARTÍNEZROMERO et al., 2003). Alternativamente, GROPPA \& BENAVIDES (2008) reportaram que o conteúdo de Put e Spm não sofre significativa alteração em cultivares de pepino tolerantes ao frio. Neste mesmo estudo, porém, foi verificado que o conteúdo de Spd aumenta em cultivares de pepino tolerantes, enquanto que nas cultivares sensíveis ao frio o conteúdo não é afetado.

De maneira geral, foram observados três momentos distintos, em que os níveis de Spd foram alterados ao longo do armazenamento (Figura 4C). Aos 15 dias, os frutos controle e os tratados com ácido salicílico exibiram superior acréscimo em relação ao conteúdo observado nos frutos tratados com etileno ou 1-MCP. Aos 60 dias, apenas os frutos não tratados exibiram elevação nos níveis de Spd. No período subsequente, aos 75 dias, enquanto os níveis de Spd permaneceram baixos nos frutos controle e nos tratados com etileno, houve significativo acréscimo nos níveis de Spd, nos frutos tratados com 1-MCP ou ácido salicílico. Ao final do armazenamento, o teor de poliaminas (Put, Spm, Spd) foi semelhante em todos os tratamentos (Figura 4). Tem sido sugerido que o acúmulo de poliaminas nos tecidos pode conferir maior tolerância a variados tipos de estresse devido a essas aminas atuarem na remoção de espécies reativas de oxigênio e também auxiliarem a estabilização das membranas celulares (LARHER et al., 2003; GROPPA \& BENAVIDES, 2008). Contudo, no presente trabalho,

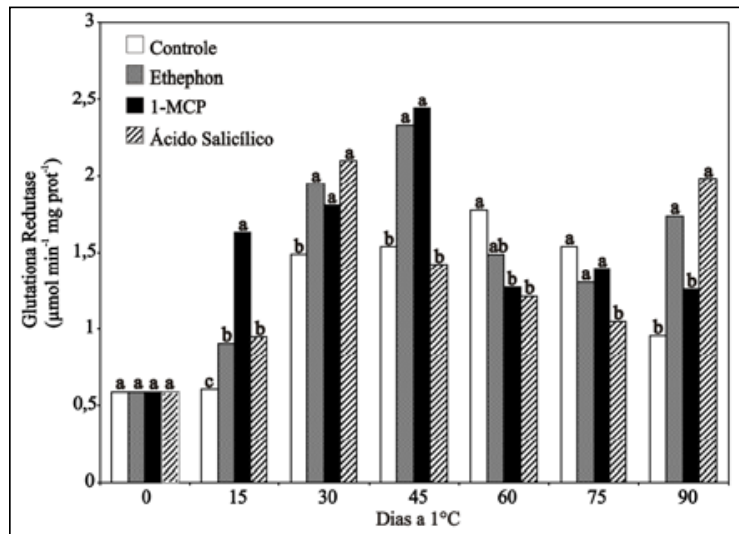

Figura 3 - Atividade específica de GR no flavedo de tangor 'Murcott' tratado com ethephon, 1-MCP ou ácido salicílico e armazenado a $1^{\circ} \mathrm{C}$, durante 90 dias. Tratamentos com médias não seguidas pela mesma letra diferem pelo teste de Tukey $(\mathrm{P} \leq 0,05)$. 


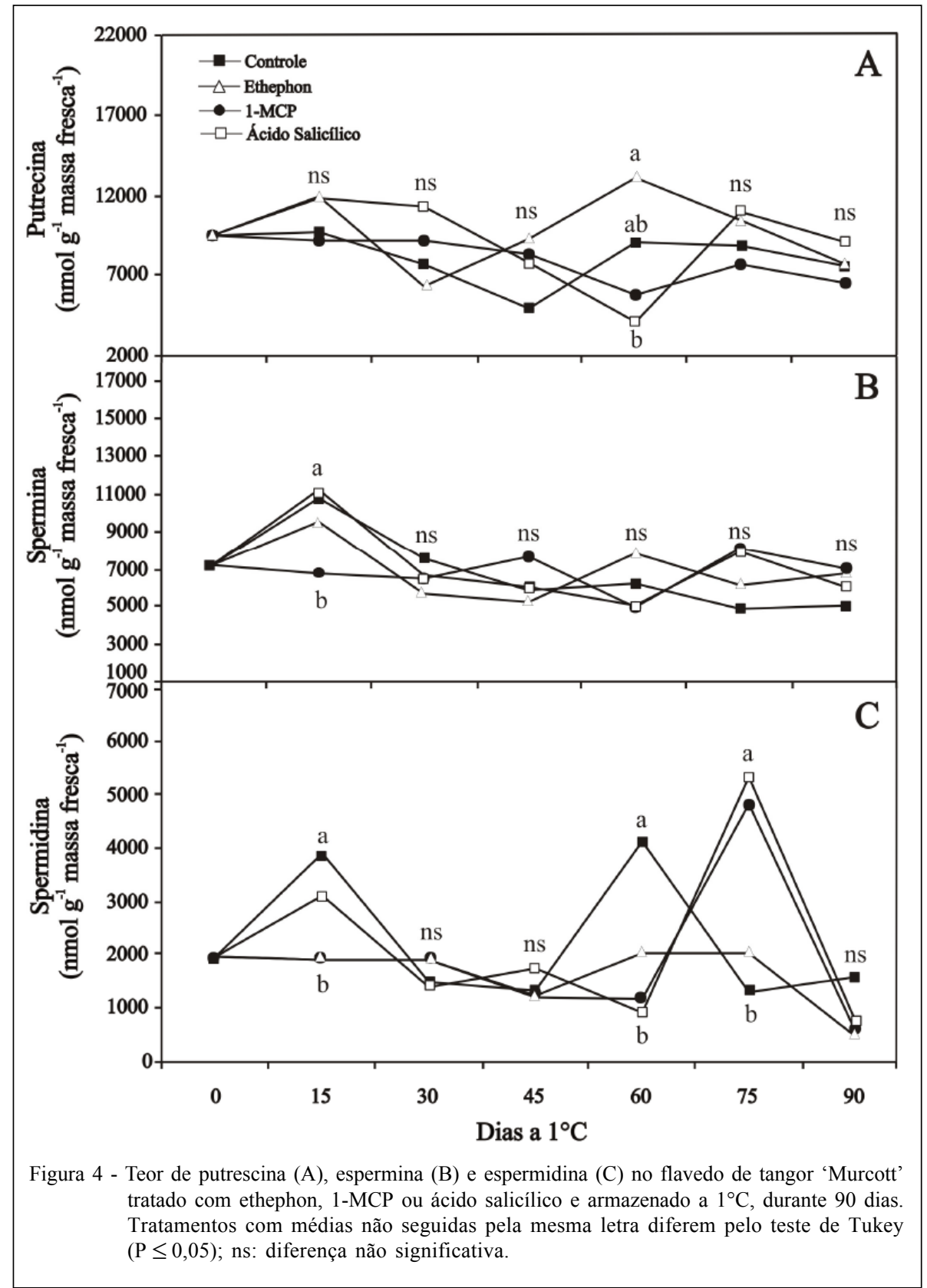

não foi evidenciada relação direta entre os níveis de poliaminas e a incidência de injúrias de frio nos frutos. Em estudo realizado com cultivares de tangerina tolerantes e sensíveis às injúrias de frio, SALA (1998) concluiu que a tolerância ao frio pode estar relacionada à eficiência com que o sistema antioxidante remove intermediários tóxicos da célula, como o peróxido de hidrogênio. Dessa forma, a avaliação de outras enzimas envolvidas na defesa antioxidante poderá contribuir para um melhor entendimento da relação entre as injúrias de frio, o sistema antioxidante e o papel do etileno nesse processo.

\section{CONCLUSÃO}

A exposição de tangores 'Murcott' ao 1$\mathrm{MCP}$ antes do armazenamento a $1{ }^{\circ} \mathrm{C}$ reduz as injúrias de frio.

Não há relação direta entre o conteúdo de poliaminas no flavedo dos frutos e a tolerância à baixa temperatura.

\section{REFERÊNCIAS}

BRADFORD, M.M. A rapid and sensitive method for the quantitation of microgram quantities of protein utilizing the 
principle of protein-dye binding. Analytical Biochemistry, v.72, p.248-254, 1976

GAMBLE, P.E.; BURKE, J.J. Effect of water stress on the chloroplast antioxidant system. Alterations in glutathione reductase activity. Plant Physiology, v.76, p.615-621, 1984.

GROPPA, M.D.; BENAVIDES, M.P. Polyamines and abiotic stress: recent advance. Amino Acids, v.34, p.35-45, 2008. Disponível em: <http://dx.doi.org/10.1007/s00726-007-05018 >. Acesso em: 26 abr. 2010. doi: 10.1007/s00726-0070501-8.

LAFUENTE, M.T. et al. Phenylalanine ammonialyase as related to ethylene in the development of chilling symptoms during cold storage of citrus fruits. Journal of Agricultural and Food Chemistry, v.49, p.6020-6025, 2001. Disponível em: <http://dx.doi.org/10.1021/jf010790b $>$. Acesso em: 26 abr. 2010. doi: 10.1021/jf010790b.

LARHER, F.R. et al. An assessment of the physiological properties of the so-called compatible solutes using in vitro experiments with leaf discs. Plant Physiology and Biochemistry, v.41, p.657-666, 2003. Disponível em: $<$ http:/ /dx.doi.org/10.1016/S0981-9428(03)00076-7 >. Acesso em: 26 abr. 2010. doi: 10.1016/S0981-9428(03)00076-7.

LIMA, G.P.P. et al. Poliaminas e atividade da peroxidase em feijão (Phaseolus vulgaris L.) cultivado sob estresse salino. Scientia Agricola, v.56, p.21-25, 1999.

MARANGONI, A.G. et al. Membrane effects in postharvest physiology. Postharvest Biology and Technology, v.7, p.193-217, 1996

MARTÍNEZ-ROMERO, D. et al. Physiological changes in pepino (Solanum muricatum Ait.) fruit stored at chilling and non-chilling temperatures. Postharvest Biology and Technology, v.30 p.177-186, 2003.

MITTLER, R. Oxidative stress, antioxidants and stress tolerance. Trends in Plant Science, v.7, p.405-410, 2002. Disponível em: <http://dx.doi.org/10.1016/S13601385(02)02312-9>. Acesso em: 26 abr. 2010. doi: 10.1016/ S1360-1385(02)02312-9.

PORAT, R. et al. Effects of ethylene and 1methylcyclopropene on the postharvest qualities of Shamouti oranges. Postharvest Biology and Technology, v.15, p.155-163, 1999.

RODRIGUEZ, S.C. et al. Effect of different treatments on the evolution of polyamines during refrigerated storage of eggplants. Journal of Agriculture and Food Chemistry, v.49, p.4700-4705, 2001.
SALA, J.M. Involvement of oxidative stress in chilling injury in cold-stored mandarin fruits. Postharvest Biology and Technology, v.13, p.255-261, 1998.

SALA, J.M.; LAFUENTE, M.T. Catalase in the heat-induced chilling tolerance of cold-stored hybrid Fortune mandarin fruits. Journal of Agriculture and Food Chemistry, v.47, p.2410-2414, 1999.

SALVADOR, A. et al. 1-MCP Effect on chilling injury development in 'Nova' and 'Ortanique' mandarins. Food Science and Technology International, v.12, p.165-170, 2006.

SAYYAR, M. et al. Effect of salicylic acid treatment on reducing chilling injury in stored pomegranates. Postharvest Biology and Technology, v.53, p.152-154, 2009.

SELVARAJAH, S. et al. Internal browning in cold-stored pineapples is suppressed by a postharvest application of 1methylcyclopropene. Postharvest Biology and Technology, v.23, p.167-170, 2001.

SERRANO, M. et al. Review: role of polyamines in chilling injury of fruit and vegetables. Food Science and Technology International, v.2, p.195-199, 1996.

SMITH, I.S. et al. Assay of glutathione reductase in crude tissue homogenates using 5,5'-dithiobis (2-nitrobenzoic acid). Analytical Biochemistry, v.175, p.408-413, 1988.

VITÓRIA A.P. et. al. Antioxidant enzymes responses to cadmium in radish tissues. Phytochemistry, v.57, p.701710,2001 .

XU, X.; TIAN, S. Salicylic acid alleviated pathogen-induced oxidative stress in harvested sweet cherry fruit. Postharvest Biology and Technology, v.49, p.379-385, 2008.

WANG, C.Y. Physiological and biochemical responses of plants to chilling stress. HortScience, v.17, p.173-186, 1982.

WANG, L. et al. Salicylic acid pretreatment alleviates chilling injury and affects the antioxidant system and heat shock proteins of peaches during cold storage. Postharvest Biology and Technology, v.41, p.244-251, 2006. Disponível em:<http://dx.doi.org/ 10.1016/j.postharvbio.2006.04.010>. Acesso em: 26 abr. 2010. doi: 10.1016/ j.postharvbio.2006.04.010.

WISMER, W.V. Low temperature as a causative agent of oxidative stress in postharvest crops. In: HODGES, D.M. Postharvest oxidative stress in horticultural crops. New York: Food Product Press, 2003. 266p. 